\title{
Viabilidade do aproveitamento agrícola de percolados de resíduos sólidos urbanos
}

\author{
Antonio T. de Matos ${ }^{1}$, André L. de Carvalho ${ }^{1} \&$ lzabel C. D. d'A. Azevedo
}

\section{RESU M O}

Com a realização deste trabalho, avaliou-se a qualidade física, química e bioquímica do percolado produzido em colunas de resíduo sólido urbano recém-coletado (RSU), contendo ou não camada de resíduo de construção civil (RCC), com fins de aproveitamento agrícola; para isso, o RSU foi colocado, de forma seqüencial em camadas de 0,15 m de espessura e peso específico de $7 \mathrm{kN} \mathrm{m}^{-3}$, obtidas por compressão do material acondicionado, formando-se ao final duas colunas com 2,47 m de altura. Em uma das colunas, antes do acondicionamento do RSU, foi disposta uma camada de 0,30 m de RCC, como base para a coluna. Amostras do percolado lixiviado das colunas foram coletadas quinzenalmente para a realização das seguintes caracterizações: CE, pH, ST, SST, DQ O, DBO, N total, Ca, Mg, Fe, Mn, Cd, Cu, Zn, Pb, N i e Cr. Com base nos relativamente altos valores de $\mathrm{pH}$ e de concentrações de material orgânico e macronutrientes ( $\mathrm{N}, \mathrm{Ca}, \mathrm{Mg}$ ) e de baixas concentrações de metais pesados, o uso dos percolados de aterros sanitários deve ser considerado como forma viável de disposição final dessa água residuária.

Palavras-chave: aterro sanitário, chorume, lixo urbano

\section{Viability of the use of leachate from the urban solid residues in agriculture}

\begin{abstract}
This study aimed to evaluate the physical, chemical and biochemical characteristics of the percolate produced by recently collected solid residue (RSU) columns with or without residue layer from building demolition (RCC). For this, the RSU was sequentially conditioned in layers of $0.15 \mathrm{~m}$ and $7 \mathrm{kN} \mathrm{m}^{-3}$ density to obtain two columns of $2.47 \mathrm{~m}$ height. One of the columns received a RCC $0.30 \mathrm{~cm}$ layer, positioned at its base. Samples of the leachate were collected every fifteen days for the following characterization: $\mathrm{pH}, \mathrm{EC}$ and concentration of TS, TSS, COD, BOD, total N, Ca, M g, Fe, M n, Cd, $\mathrm{Cu}, \mathrm{Zn}, \mathrm{Pb}, \mathrm{Ni}$ and $\mathrm{Cr}$. The presence of the RCC layer in the columns provided no alterations in EC, but caused a decrease in concentrations of BOD, COD, TOC, TS, TSS, Ca, Mn and Fe in the leachate. Based on high values of pH, organic matter and macronutrient concentrations ( $\mathrm{N}, \mathrm{Ca}$ and $\mathrm{Mg}$ ) and low concentrations of heavy metals, the landfill leachate for fertirrigation must be considered as a viable form of final disposal of this wastewater.
\end{abstract}

Key w ords: landfill, leachates, urban residues 


\section{INTRODUÇÃO}

A gestão e a destinação final dos resíduos sólidos urbanos (RSU), comumente denominados lixo, constituem grandes problemas a serem enfrentados pela humanidade. No Brasil, este é um problema de grande dimensão ante o enorme volume gerado e a forma, na maioria das vezes inadequada, em que o resíduo tem sido gerenciado e disposto (Carvalho et al., 2006).

O aterramento sanitário do RSU visa evitar a sua exposição na superfície do solo, o que pode causar danos à saúde pública, e minimizar os impactos ambientais por eles provocados (ABNT, 1984). Mesmo aterrado, o RSU gera um líquido de coloração escura, altamente poluidor, denominado percolado, formado pela mistura do "chorume", resultante da degradação e solubilização do material orgânico do RSU, com a água infiltrada no aterro. A fonte de água de percolação pode ser a precipitação, irrigação, águas subterrâneas ou percolados recirculados através do aterro (Qian et al., 2002).

Qian et al. (2002) relataram uma produção de percolados entre 2 e $3 \mathrm{~mm} \mathrm{~d}^{-1}$ em aterros sanitários de Nova York. Carvalho et al. (2006) obtiveram lâminas de percolado de $5 \mathrm{~mm} \mathrm{~d}^{-1}$ em colunas de RSU recém-coletado, contendo camada de $0,30 \mathrm{~m}$ de resíduo da construção civil (RCC) na sua base, enquanto naquela que não a continha a lâmina média obtida foi de $3,9 \mathrm{~mm} \mathrm{~d}^{-1}$.

O tratamento do percolado captado pelas redes de drenagem em aterros sanitários representa, ainda, grande impasse na elaboração dos projetos de aterros sanitários, uma vez que suas características são alteradas em função da quantidade de água incorporada ao chorume, das características dos resíduos dispostos no aterro e, principalmente, da idade do aterro (Ferreira et al., 2001); além disso, a exigência de grandes áreas

A.

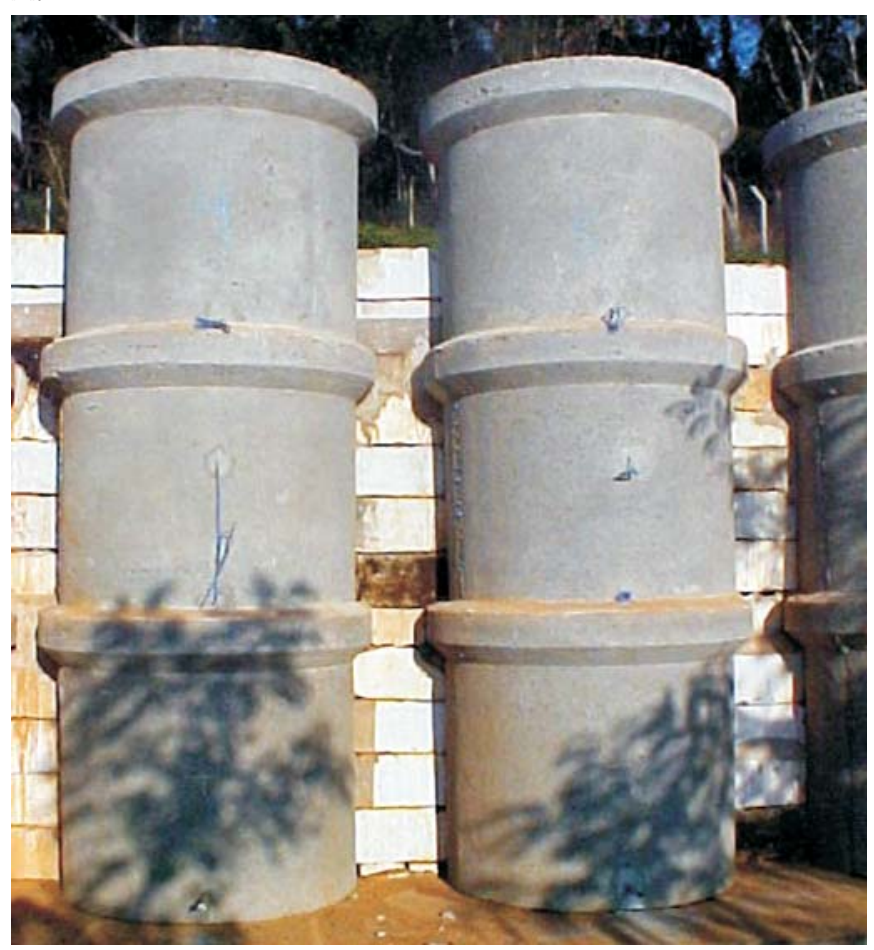

e a relativa baixa eficiência do sistema convencional de tratamento (lagoas anaeróbias seguidas de facultativas), têm levado técnicos e pesquisadores a procurarem alternativas técnicas que possibilitem o tratamento/disposição final com menor custo econômico e ambiental.

O aproveitamento de águas residuárias ricas em material orgânico tem sido adotado com freqüência, como forma de disposição final adequada desses resíduos, concorrendo para que se obtenha melhoria na qualidade do solo, possibilitando a obtenção de aumento na produtividade de muitas culturas agrícolas (Matos et al., 2003).

Considerando-se que o percolado produzido em aterros sanitários apresenta potencialidades para uso em fertirrigação de culturas agrícolas, objetivou-se, com a realização deste trabalho, avaliar a qualidade física, química e bioquímica do percolado produzido em colunas de RSU, contendo ou não camada de RCC, com fins de aproveitamento agrícola.

\section{MATERIAL E MÉTODOS}

O experimento foi conduzido na Área Experimental de Tratamento de Resíduos Urbanos do Departamento de Engenharia Agrícola da Universidade Federal de Viçosa, MG. Para o desenvolvimento das atividades de pesquisa, duas colunas de resíduo foram montadas, que foram acondicionadas em três manilhas de concreto armado com 1,00 m de diâmetro interno e $1,00 \mathrm{~m}$ de altura, sobrepostas, formando um cilindro rígido de 3,00 $\mathrm{m}$ de altura (Figura 1A). As colunas foram encostadas em talude de solo e apoiadas sobre uma laje de concreto armado, para maior estabilidade e minimizar vazamentos; a base de cada coluna foi construída com pequena declividade para que o per-

B.

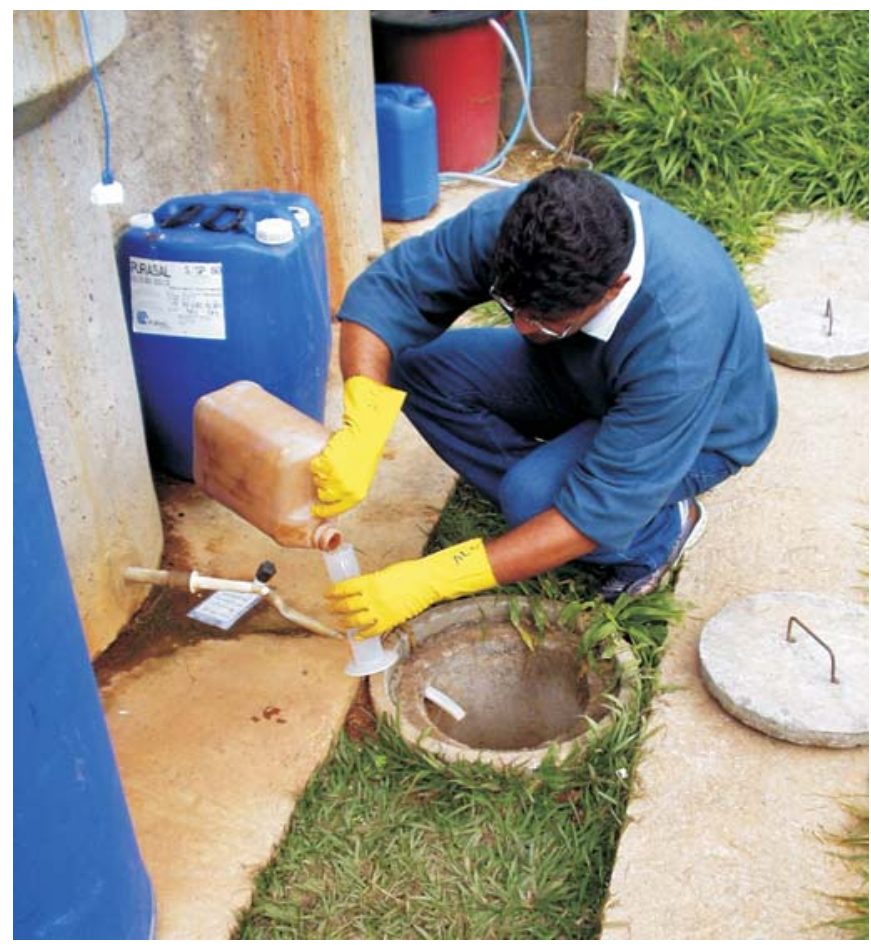

Figura 1. Detalhe das colunas de RSU (A) e da coleta de amostras de percolado nos drenos posicionados nas bases das colunas (B) 
colado fosse conduzido para uma tubulação de PVC de $25 \mathrm{~mm}$ de diâmetro, que atravessava toda a parede da coluna e tinha, em sua extremidade, uma torneira, também de PVC, com a finalidade de facilitar a coleta desse líquido (Figura 1B).

As colunas receberam, nas suas bases, camadas de brita $\mathrm{n}^{\circ} 1$ e areia grossa, para drenagem do percolado e para se avaliar o efeito da camada de RSU na qualidade do percolado, na coluna denominada CCE, dispôs-se uma camada de $0,30 \mathrm{~m}$ de RCC sobre a camada de brita. Na coluna denominada CSE foi acondicionado apenas RSU sobre a camada de brita. Em ambas as colunas, o RSU foi acondicionado de forma seqüencial, por camadas de $0,15 \mathrm{~m}$ de espessura, as quais foram comprimidas de forma a se estabelecer um peso específico de $7 \mathrm{kN} \mathrm{m}^{-3}$ no material, conforme considerado em projeto de aterros sanitários por Azevedo (2002); por sua vez, as camadas de RSU foram sobrepostas até ser atingida altura de 2,47 m. No topo das colunas, sobre as colunas de RSU, acondicionou-se uma camada de 0,35 $\mathrm{m}$ de espessura, de brita e areia grossa, para facilitar e homogeneizar a infiltração da água de chuva e do percolado recirculado.

Antes do preenchimento das colunas com RSU recém-coletado, gerado na cidade de Viçosa, MG, fez-se a determinação da composição gravimétrica desse material, utilizando-se a técnica do quarteamento para obtenção de uma amostra homogênea de RSU, cujo material foi classificado e sua massa determinada, sendo o material constituinte do RSU, respectivamente, distribuído para a CSE e CCE: 14,5 e 15,0 de papel/papelão, 14,5 e 18,8\% de plástico fino, 3,0 e 2,8\% de plástico duro, 0,5 e $1,2 \%$ de PET, 1,8 e $4,3 \%$ de vidro, 0,1 e $0,8 \%$ de alumínio, 1,8 e $1,5 \%$ de metais, 62,8 e $52,4 \%$ de material orgânico 1,0 e 3,2\% de outros. As diferenças na composição foram devidas ao RSU ser proveniente de dois bairros diferentes da cidade.

O RCC colocado na base da coluna CCE, foi coletado em local de demolição, predominantemente de paredes; o material foi quebrado e peneirado, de forma a ser obter granulometria entre 2 e $10 \mathrm{~cm}$ de tamanho.

No período de monitoramento do sistema, realizado por um ano, foram coletadas amostras quinzenais, encaminhadas depois para medição do pH e da CE e quantificação das concentrações de DBO, DQO, ST, SST e nitrogênio total (NT) no Laboratório de Qualidade da Água, do Departamento de Engenharia Agrícola/UFV, enquanto as de concentração total de $\mathrm{Zn}, \mathrm{Cd}, \mathrm{Cu}, \mathrm{Pb}, \mathrm{Ni}, \mathrm{Mn}, \mathrm{Cr}, \mathrm{Fe}, \mathrm{Ca}$ e $\mathrm{Mg}$ foram quantificadas no Laboratório de Espectrometria por Absorção Atômica, do Departamento de Solos/UFV.

$\mathrm{O} \mathrm{pH}$ e a condutividade elétrica foram medidos pelo método eletrométrico; a DBO foi quantificada pelo método iodométrico; a DQO, pelo método do refluxo aberto; o carbono orgânico total, pelo método da oxidação do material orgânico com dicromato de potássio, em meio sulfúrico; o nitrogênio total, pelo método Kjeldahl; obteve-se a concentração de sólidos totais (ST) após a secagem do líquido em estufa, sob temperatura de $103-105{ }^{\circ} \mathrm{C}$; obtiveram-se os sólidos em suspensão total (SST) com a passagem das amostras de percolado em papel filtro (Whatman, diâmetro de poro de $0,47 \mu \mathrm{m})$; as concentrações totais dos metais ( $\mathrm{Zn}, \mathrm{Cd}, \mathrm{Cu}$, $\mathrm{Pb}, \mathrm{Ni}, \mathrm{Mg}, \mathrm{Mn}, \mathrm{Fe}, \mathrm{Cr}$ e $\mathrm{Ca}$ ) foram quantificadas, após di- gestão nítrico-perclórico das amostras, em Espectrofotômetro por Absorção Atômica.

Todas as análises foram executadas seguindo-se os métodos apresentados no Standard Methods for the Examination (APHA, 1995).

Os dados de precipitação e de temperatura do ar foram obtidos no período de coleta de percolados, na Estação Meteorológica de Viçosa, MG. Na Tabela 1 está apresentado um resumo mensal dos resultados de produção de percolado nas colunas e os dados meteorológicos coletados ao longo do período experimental.

Tabela 1. Dados meteorológicos e de média mensal de líquido percolado nas colunas

\begin{tabular}{lcc}
\hline Meses & $\mathbf{T}_{\text {média }}\left({ }^{\circ} \mathrm{C}\right)$ & Precipitação $(\mathbf{m m})$ \\
\hline Agosto/2003 & 16,28 & 41,20 \\
Setembro/2003 & 18,44 & 36,50 \\
Outubro/2003 & 19,96 & 29,80 \\
Novembro/2003 & 20,72 & 109,80 \\
Dezembro/2003 & 21,72 & 219,40 \\
Janeiro/2004 & 20,95 & 271,80 \\
Fevereiro/2004 & 20,99 & 298,80 \\
Março/2004 & 20,73 & 129,40 \\
Abril/2004 & 20,13 & 111,20 \\
Maio/2004 & 17,76 & 33,80 \\
Junho/2004 & 15,50 & 45,40 \\
Julho/2004 & 15,31 & 35,20 \\
Agosto/2004 & 16,47 & 2,00 \\
\hline Total anual $(\mathrm{mm})$ & & 1.364 \\
\hline
\end{tabular}

\section{RESULTADOS E DISCUSSÃO}

$\mathrm{O}$ pH no percolado coletado na CSE (Figura 2A) manteve-se ácido no período inicial do monitoramento (primeiros 130 dias de produção de percolado) mas, com a degradação do material orgânico, a fase de degradação ácida se foi encerrando e as bases solubilizadas do material orgânico passaram a gerar um efluente de caráter neutro a alcalino. $\mathrm{O}$ $\mathrm{pH}$ do percolado da coluna CCE passou a ser mais alto que o do CSE, a partir do $196^{\circ}$ dia de operação do sistema, porém, a partir do $266^{\circ}$ dia, se igualou nas duas colunas e se manteve na faixa de 7 a 8 , condição característica da fase metanogênica de degradação biológica. A mais rápida neutralização da acidez do percolado na coluna CCE se deveu à presença da camada de RCC, que proporcionou, pela presença de carbonatos e hidróxidos contidos no cimento e na cal, a neutralização da acidez no percolado.

Os valores obtidos de $\mathrm{pH}$ indicaram que apenas nos primeiros 6 meses de aterramento do RSU o percolado produzido se apresentou ácido; entretanto, ainda em condições não prejudiciais ao desenvolvimento das plantas (CFSEMG, 1999); a partir daí, a disposição dessa água residuária no solo deverá concorrer para aumentar o $\mathrm{pH}$ do solo podendo, neste caso, ser até usada para corrigir a acidez de muitos solos ácidos.

Os valores de condutividade elétrica (CE) no percolado das colunas com e sem a camada de RCC (Figura 2B) foram altos em razão da intensiva solubilização de íons e degradação do material orgânico nas colunas de RSU. Verificou-se ten- 
A.

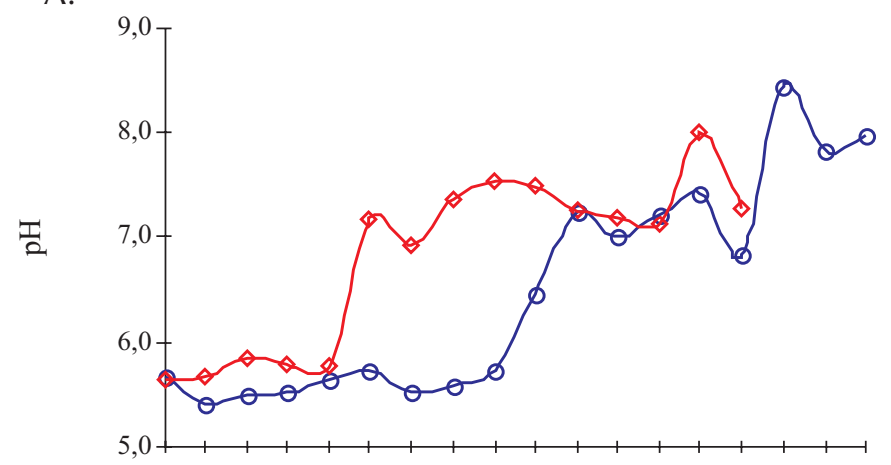

C.

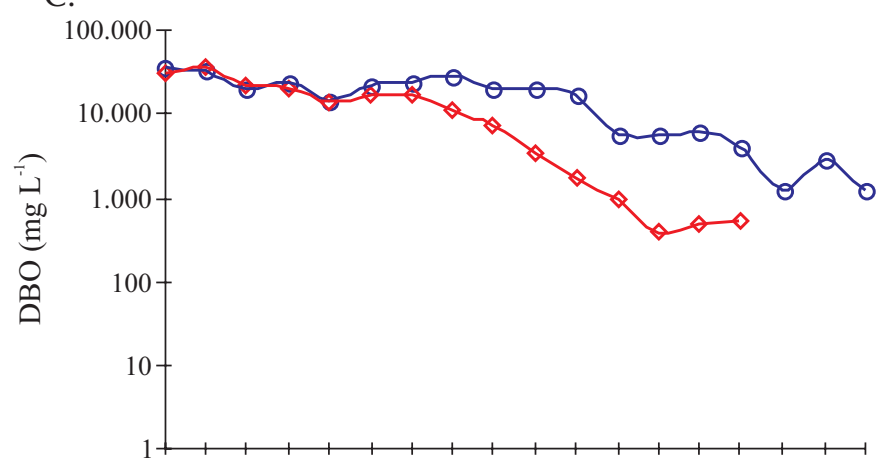

E.

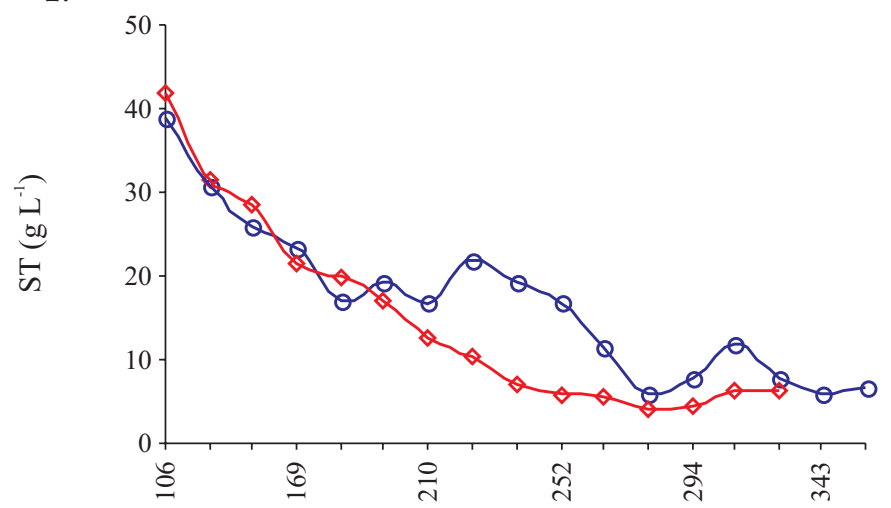

B.

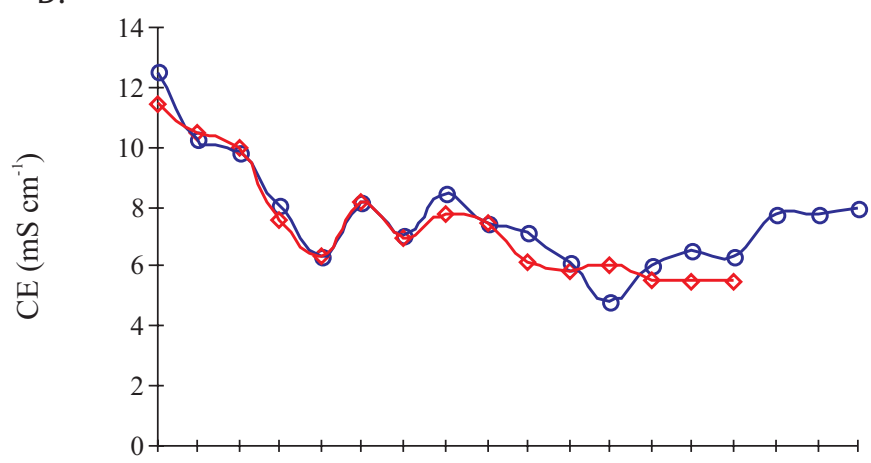

D.

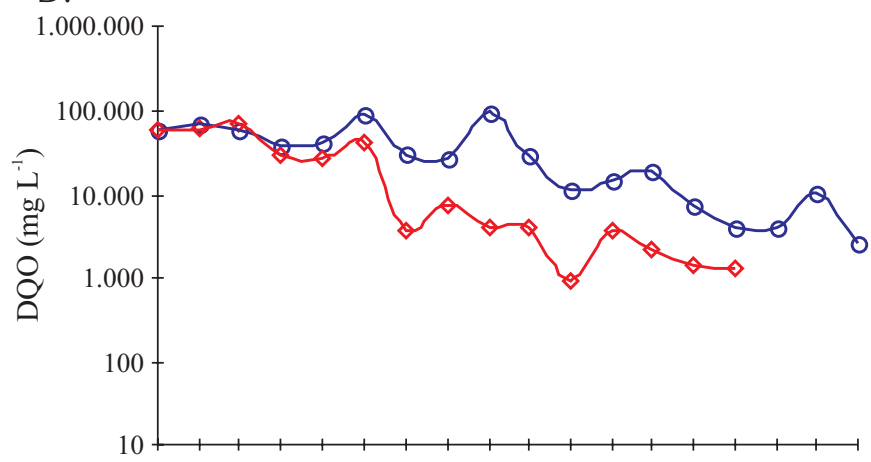

F.

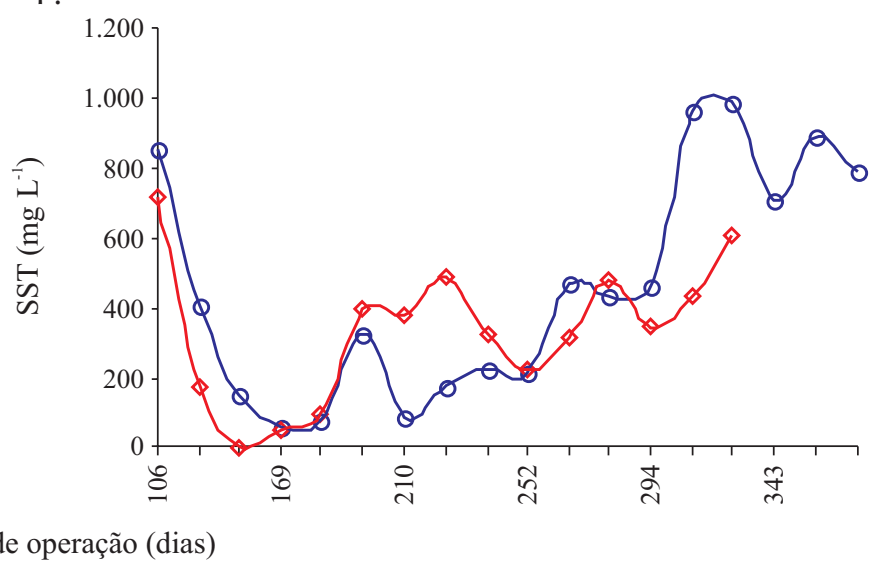

Figura 2. Evolução temporal do pH (A) condutividade elétrica (B) DBO (C) e DQO (D), ST (E), SST (F) no percolado das colunas sem (O) e com ( $\gg)$ camada de resíduo da construção civil

dência de redução nos valores de CE com o tempo de operação do sistema e, de maneira geral, a presença da camada de entulho não proporcionou efeitos consideráveis na $\mathrm{CE}$ do percolado; entretanto, durante o período de monitoramento, o percolado produzido apresentou salinidade considerada muito alta, segundo a classificação proposta pela USDA (Bernardo, 1989). Águas assim classificadas, só devem ser usadas como irrigação, ocasionalmente, em condições especiais, o que indica que deve ser utilizada como fertirrigação, respeitandose a capacidade de suporte do sistema solo-planta, no local de cultivo; em vista disso, para a disposição do percolado de RSU de forma adequada no solo, o risco de salinização do solo deverá ser, obrigatoriamente, considerado, sendo a quantidade de sais passível de ser suportada pelo sistema solo-planta importante na definição das lâminas de fertirrigação com o percolado de RSU e o monitoramento da condutividade elétrica do solo receptor fundamental para avaliação da sustentabilidade e dos riscos ambientais da prática, especialmente em regiões de baixo índice pluviométrico.

A DBO, inicialmente muito alta nas colunas CSE e CCE, diminuiu ao longo do período de operação do sistema (Figura 2C) mas, a partir do $210^{\circ}$ dia, começou a diminuir mais rapidamente na $\mathrm{CCE}$. A menor quantidade de material orgânico na CCE e a possível formação de um biofiltro no sistema podem ser as razões para o ocorrido.

Loher (1984) recomendou a aplicação de até $750 \mathrm{~kg} \mathrm{ha}^{-1} \mathrm{~d}^{-1}$ de DBO, no caso de disposição de águas residuárias ricas em material orgânico no solo. Queiroz et al. (2004) verificaram efeitos positivos e pequeno risco ambiental com a aplicação de água residuária da suinocultura, na taxa de $800 \mathrm{~kg} \mathrm{ha}^{-1} \mathrm{~d}^{-1}$ 
de DBO, em solo cultivado com gramíneas. Com base nos dados de produção de percolados, apresentados por Carvalho et al. (2006) para colunas de RSU sem e com camada de RCC, e na DBO inicial do percolado, estima-se serem necessários, respectivamente, 3,3 e 2,6 ha de área para disposição dessa água residuária, para cada hectare de aterro sanitário com células de lixo recém-coletado, de 2,47 $\mathrm{m}$ de altura. Com o passar do tempo de aterramento do RSU, a área necessária deverá diminuir para próximo de 0,1 ha por hectare de área de aterro.

Na Figura 2D está mostrada a concentração de DQO no percolado das colunas, observando-se comportamento muito semelhante ao obtido para a DBO, podendo as mesmas discussões serem estendidas a essas variáveis.

Pode-se perceber, na Figura 2E, decréscimo nos valores de ST com o tempo, tendo-se observado maior remoção na CCE, o que pode ser decorrente da menor velocidade de escoamento do líquido, em razão da menor permeabilidade nessa coluna.

Nos primeiros 4 meses de experimentação, a concentração de SST nos percolados do CSE e CCE se manteve próxima (Figura 2F) porém, a partir daí, os valores das concentrações do CSE divergiram dos obtidos no CCE, o que pode ter ocorrido por influência da presença da camada de RCC. Acredita-se que isso se deva ao efeito de filtração proporcionado por esta camada.

Os valores de SST encontrados estão altos e devem proporcionar entupimento de sistemas de aplicação localizada já que, segundo Bucks et al. (1979), concentrações de SST maiores que $100 \mathrm{mg} \mathrm{L}^{-1}$ proporcionam severo risco de obstrução de gotejadores. Com base nisto, a aplicação deve ser, necessariamente, efetuada por superfície (sulcos, corrugação, entre outras) ou por aspersão de média ou alta pressão. As maiores concentrações de ST em relação a SST indica predominância de partículas dissolvidas no percolado.

A concentração de NT nos percolados das colunas CSE e CCE (Figura 3A) diminuiu ao longo do período de operação do sistema. O comportamento das curvas foi semelhante ao observado para condutividade elétrica no percolado (Figura 2B), o que pode ser indicativo de que a maior parte do NT encontrada no percolado deve estar na forma solúvel. De maneira geral, a presença da camada de RCC não proporcionou efeitos consideráveis na remoção de NT do percolado. O nitrogênio total tem sido usado como nutriente referencial para estabelecimento das doses a serem aplicadas em solo de cultivo agrícola.

A presença de camada de RCC proporcionou redução na concentração de Ca no percolado do CCE (Figura 3A), principalmente a partir dos $183^{\circ}$ dias de operação do sistema, o que pode ter ocorrido em decorrência da formação de precipitados com pares aniônicos presentes na cal e cimento, contidos no RCC, ou mesmo por troca iônica com outros cátions de menor força de adsorção ao complexo sortivo.

Ainda que a concentração de macronutrientes $(\mathrm{N}, \mathrm{Ca}$ e $\mathrm{Mg}$ ) no percolado tenha diminuído com o tempo de aterramento do RSU, as concentrações presentes são um indicativo de que o percolado possui considerável valor fertilizante e, por esta razão, se adequadamente disposto no solo, poderá possibilitar o seu aproveitamento na fertilização do solo para a produção agro-silvo-pastoril.
A.

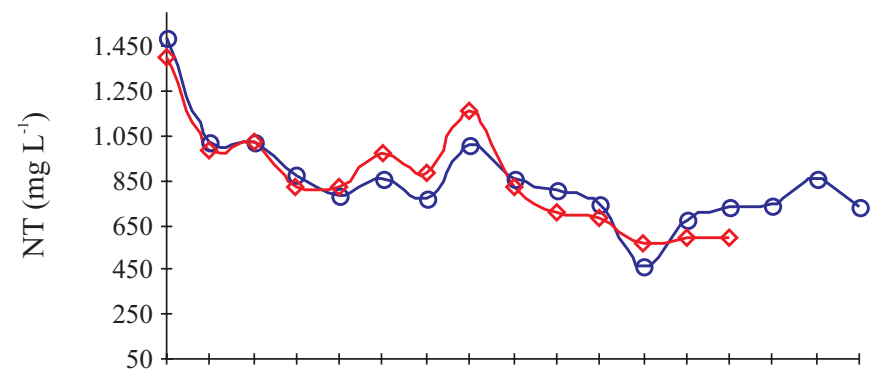

B.

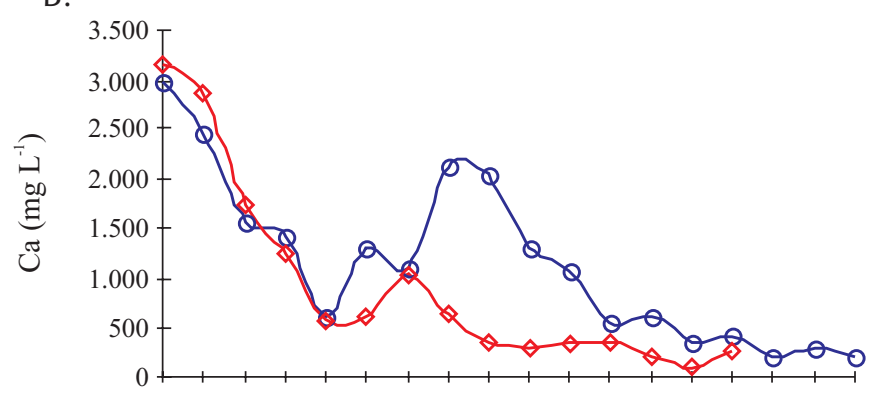

C.

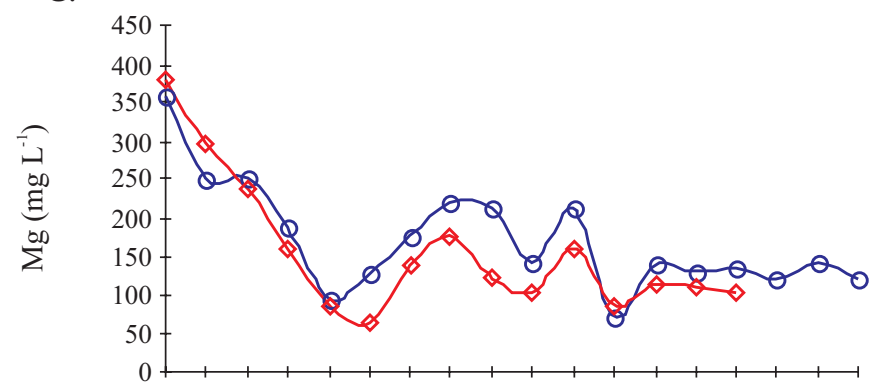

D.

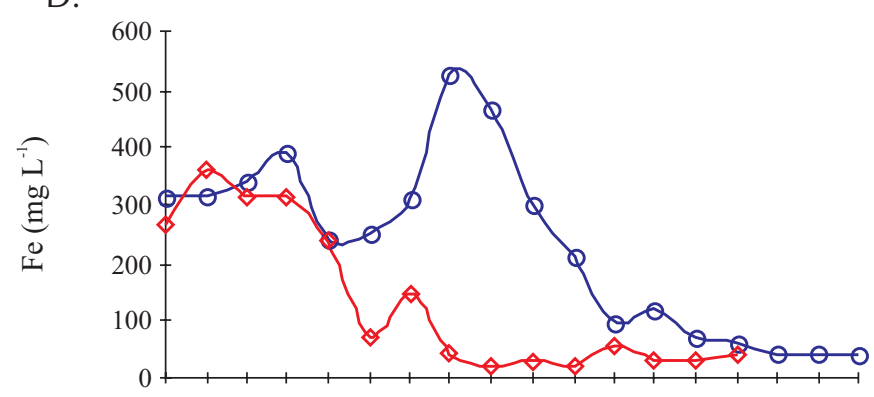

E.

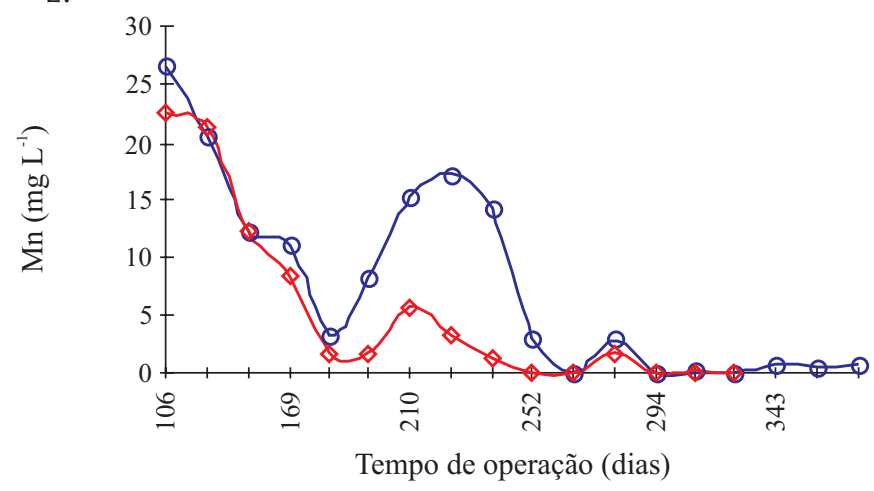

Figura 3. Evolução temporal na concentração de NT (A), Ca (B), Mg (C), $\mathrm{Fe}(\mathrm{D})$ e $\mathrm{Mn}(\mathrm{E})$ no percolado das colunas sem $(\mathrm{O})$ e com $(\diamond)$ camada de resíduo da construção civil 
O percolado das colunas apresentou altas concentrações de Fe total (Figura 3C), notadamente na CCE (Figura 3D). Da mesma forma como ocorreu nas curvas de concentração de $\mathrm{Ca}$ e $\mathrm{Mn}$ (Figuras 3A e 3C), a concentração de Fe total no percolado do CSE aumentou entre os $183^{\circ}$ e $266^{\circ}$ dias de operação do sistema, período em que a presença da camada de RCC proporcionou redução na concentração desse metal no percolado do CCE.

A formação de precipitados e, ou, a complexação/quelação no material orgânico de grande superfície específica, retido na camada RCC, podem ser as razões para o ocorrido.

Inicialmente, as concentrações de $\mathrm{Mn}$ no percolado das colunas eram altas (Figura 3E), com o tempo, decresceram mas, ainda assim, a título de comparação, se mantiveram superiores ao padrão para lançamento em corpos receptores, estabelecidos na Resolução CONAMA n 357/2005 (SEMAD, 2007), que é de $1,0 \mathrm{mg} \mathrm{L}^{-1}$ porém, por se tratar de micronutriente para as plantas, sua presença, nas concentrações tal como as encontradas, deve proporcionar efeitos benéficos ao desenvolvimento das plantas. No período de 183 a 252 dias de operação do sistema, a concentração de Mn no percolado do CCE esteve muito abaixo da encontrada no percolado do CSE creditando-se, à presença da camada de RCC, os resultados obtidos.

De acordo com as considerações apresentadas por Bucks et al. (1979), os percolados, em todo o período de monitoramento, no que se refere ao ferro, e nos primeiros 10 meses de operação do sistema, em relação ao manganês, apresentaram concentrações de metais que proporcionam risco severo de entupimento de gotejadores. Esses resultados corroboram o que foi afirmado em relação à concentração de SST no percolado, sendo contra-indicativo o uso de sistemas para aplicação localizada dos percolados no solo.

As concentrações de cádmio, cobre, crômio, chumbo, níquel e zinco estão, na grande maioria das vezes, inferiores aos limites de detecção do aparelho utilizado. No que se refere a esses metais pesados, o percolado apresentou-se, durante todo o período de monitoramento, em condições de lançamento em corpos hídricos receptores, de acordo com os padrões estabelecidos na Resolução CONAMA 357/2005, indicando pequeno risco para a sua disposição no solo.

\section{CONCLUSÕES}

1. O pH no percolado do CSE foi, durante cerca de 130 dias de produção, ácido, aumentando seu valor a partir daí; na CCE, a acidez no percolado foi neutralizada a partir de 77 dias de produção de percolado.

2. A CE no percolado apresentou-se alta em ambas as colunas, notadamente nas fases iniciais de produção do líquido, e a presença da camada de RCC nas colunas fez diminuir as concentrações de DBO, DQO, ST, SST, Ca, Mn e Fe no percolado.

3. A presença da camada de RCC na base das colunas de RSU fez diminuir as concentrações de macronutrientes nos percolados.
4. Com base nos altos valores de $\mathrm{pH}$ e de concentração de material orgânico e macronutrientes $(\mathrm{N}, \mathrm{Ca}, \mathrm{Mg})$ e nas baixas concentrações de metais pesados, a fertirrigação deve ser considerada como forma de disposição final de percolados de aterro sanitário.

\section{LITERATURA CITADA}

ABNT - Associação Brasileira de Normas Técnicas. NBR 8.419. Apresentação de projetos de aterros sanitários de resíduos sólidos urbanos: Procedimento. Rio de Janeiro: ABNT, 1984. 7p.

APHA - American Public Health Association. Standard methods for the examination of water and wastewater. 19.ed. Washington D. C.: AWWA/APHA/WEF, 1995. s.p.

Azevedo, R. F. Aterros sanitários. In: Encontro de Preservação de Manaciais da Zona da Mata Mineira, 2, 2002, Viçosa. Anais..., Viçosa: ABES, ABAS, DEA/UFV, 2002. p.39-87

Bernardo, S. Manual de irrigação, Viçosa: UFV, 1989. 596p.

Bucks, D. A.; Nakayama, F. S.; Gilbert, R. G. Trickle irrigation water quality and preventive maintenance. Agricultural Water Management, v.2, p.149-162, 1979.

Carvalho, A. L.; Matos, A. T.; Hamakawa, P. J.; Azevedo, R. F. Produção de percolado por resíduos sólidos urbanos de diferentes idades, na presença de resíduos da construção civil e sob recirculação. Engenharia na Agricultura, v.14, n.2, p.131$138,2006$.

CFSEMG - Comissão de Fertilidade do Solo do Estado de Minas Gerais. Recomendações para o uso de corretivos e fertilizantes em Minas Gerais. 5a . aproximação. Viçosa: CFSEMG, 1999. 359p.

Ferreira, J. A.; Giordano, G.; Ritter, E.; Rosso, T. C. A.; Campos, J. C.; Lima, P. Z. M. Uma revisão das técnicas de tratamento de chorume e a realidade do Estado do Rio de Janeiro. In: Congresso Brasileiro de Engenharia Sanitária e Ambiental, 21, 2001, João Pessoa. Anais... Rio de Janeiro: ABES, 2001, p.26-34.

Loehr, R. A. Pollution control for agriculture. New York: Academic Press, 1984. 455p.

Matos, A. T.; Brasil, M. S.; Fonseca, S. P. P. Aproveitamento de efluentes líquidos domésticos e agroindustriais na agricultura. In: Encontro de Preservação de Mananciais da Zona da Mata Mineira, 3, 2003, Viçosa. Anais... Viçosa: ABES-MG, ABASMG, DEA/UFV, 2003. p.25-79.

Qian, X.; Koerner, R. M.; Gray, D. H. Geotechnical aspects of landfill design and construction. Upper Saddle River: Prentice Hall., 2002, 717p.

Queiroz, F. M.; Matos, A. T.; Pereira, O. G.; Oliveira, R. A.; Lemos, A. F. Características químicas do solo e absorção de nutrientes por gramíneas forrageiras em rampas de tratamento de águas residuárias da suinocultura. Revista Engenharia na Agricultura, v.12, n.2, p.77-90, 2004

SEMAD - Secretaria de Estado do Meio Ambiente e do Desenvolvimento Sustentável, 2007. Legislação CONAMA 357/ 2005. http://www.siam.mg.gov.br/sla/dowload.pdr?idNorma2747, 25 Ago. 2008. 